\title{
O Ministério Público e a \\ a proteção dos Consumidores \\ Equiparados
}

Renato Moreira Dorneles

Setembro/2004

\section{SUMÁRIO}

1. Introdução. 2. A relevância do tema tlDefesa do Consumidor" na Constituição brasileira vigente. 3. Fundamentos da atuação do Ministério Público na defesa dos Consumidores. 4. 0 Consumidor para o Código de Relações de Consumo. 5. Conclusão. 6. Bibliografia.

\section{Introdução}

Escrever-se sobre o tema direito do consumidor, nos dias atuais, pode aparentar a muitos ser tarefa das mais infrutíferas. Enganam-se, data vênia, aqueles que assim pensam. O tema que dá título ao presente artigo é exemplo disso. A crescente atuação do Ministério Público na defesa dos consumidores e a amplitude de suas ações na proteção do mercado de consumoé algo muito recente, o que torna imprescindivel o exame do conceito de consumidor em sua total amplitude, assunto basilar, mas dos mais instigantes e que mais problemas apresenta na prática da aplicação do direito consumerista.

Neste sentido, vislumbramos, sim, uma necessidade premente de aprofundamento teórico-doutrinário pelos profissionais do direito, a 
fim de que se descortine, ao final, o verdadeiro alvo e alcance protetivo das normas do direito das relações de conșumo e do leque de atribuições do Ministério Público na defesa dos interesses e direitos dos consumidores, lato sensu.

O presente artigo, portanto, é uma investigação que visa a observar as bases estabelecidas pela Constituição Federal e pela legislação do Ministério Público, com vistas à proteção e defesa do mercado consumerista pelo órgão Parquet.

Neste sentido, e para uma melhor abordagem do tema aqui estudado, dividimos o presente artigo em três pontos fundamentais: - A relevância do tema defesa do consumidor na Constituição brasileira vigente; -Fundamentos da atuação do Ministério Público na defesa dos consumidores; e, - O Consumidor para o Código de Relações de Consumo.

No primeiro ponto, demonstraremos a relevância do tema defesa do consumidor em nossa Carta Maior, com o fim de destacarmos a ordem jurídica a que o Ministério Público está incumbido, também por força constitucional, de defender. No ponto a seguir, abordaremos as funções institucionais do Ministério Público previstas na Carta Magna brasileira e na legislação infraconstitucional, que autorizarn e orientarn a atuação do Parquet na proteção dos direitos e interesses difusos, coletivos e individuais homogêneos dos consumidores.

Por fim, no terceiro ponto, apresentaremos um panorama dos conceitos de consumidor constantes do Código Protetivo, com o que procuraremos demonstrar ao final deste artigo, a possível e inafastável necessidade de proteção, pelo Ministério Público, dos entes que venham a ser equiparados a consumidores, especialmente, por força do estabelecido nos artigos 17 e 29 do Código de Defesa do Consumidor, que tratam, respectivamente, das vítimas de acidentes de consumo e dos sujeitos expostos às práticas comerciais abusivas no mercado de consumo, mesmo quando quaisquer destes não se enquadrem no conceito de consumidorstricto sensu, previsto no art. $2^{\circ}$, caput do CDC. 
Enfim, esperamos, por meio deste singelo estudo, poder contribuir positivamente com o direito consumerista brasileiro, e em especial, para a completa e efetiva atuação do Ministério Público na defesa dos direitos consumeristas, disponibilizando não só aos membros do Parquet, mas a todos os interessados no tema, informações mínimas imprescindíveis para a boa compreensão e consolidação da extensão da figura do consumidore de suas relações jurídicas. Ressaltamos, pois, a importância da fixação e correta aplicação dos conceitos e definições de consumidor adiante analisados, bem como das atribuições do Ministério Público, com o que procuramos facilitar, sensivelmente, o trato diário com a matéria.

2. A relevância do tema "Defesa do Consumidor" na Constituição brasileira vigente

Para que possamos compreender a insofismável atribuição do Ministério Público na proteção e defesa dos consumidores, e via de conseqüência; do mercado consumidor brasileiro, mister terrnos presente a alta relevância do tema consumerista na Constituição Brasileira de 1988, ela que é conhecida como a constituição cidadã?.

Nesta esteira, devemos atentar, preliminarmente, para o fato de que o legislador constitucional acolheu orientação da Organização das Nações Unidas - ONU, no sentido de estabelecer entre os direitos e garantias fundamentais de todo o cidadão brasileiro e estrangeiro residente no país, a defesa do consumidor ${ }^{2}$. A Carta Magna brasileira, cumpre referir, não apenas estipulou que o direito do consumidor devesse ser garantido; foi além. Impôs expressamente ao próprio

\footnotetext{
${ }^{1}$ Assim denominada pelo então presidente da Assembléia Nacional Constituinte, Sr. Ulysses Guimarães.

${ }^{2}$ Portugal foi o primeiro país a acolher em sua Constituição Federal de 1976 (art. 110) as normas de proteção e defesa do consumidor. Foi seguida pela Constituição Espanhola de 1978 (art. 51). Assim, SILVA, José Afonso.

Curso de Direito Constitucional Positivo. São Paulo: Malheiros Editores. 1993.
} 
Estado a sua promoção (art. $5^{\circ}$, inc. $\left.X X X I 1\right)^{3}$, tendo determinado ao Congresso Nacional, naquela mesma oportunidade, o prazo de 120 dias, a contar da promulgação da Constituição da República de 1988, para que fosse elaborado o Código Brasileiro de Defesa do Consumidor (art. 48, dos Atos das Disposições Constitucionais Transitórias -ADCT ${ }^{4}$

Convém ressaltarmos, outrossim, que ao tratar dos princípios gerais que regem a economia brasileira, a Constituição Federal disciplina que a ordem econômica, baseada na valorização do trabalho humano e na livre iniciativa, deve assegurar a todos a existência digna. Neste sentido, enumera nove princípios informados no art. 170, da Constituição, dentre eles, o respeitante à defesa do consumidor.

Com efeito, da análise dos dispositivos constitucionais supramencionados, percebe-se que o legislador brasileiro atentou-se, sabiamente, para a vulnerabilidade ${ }^{5}$ dos consumidores no mercado de consumo, gerando, com isso, verdadeiro reflexo positivo na ampliação do conceito de consumidor, previstos do Código de Relações de Consumo, arts. 17 e29, conforme vermos adiante.

Assim, impôs-se ao Estado (incluído, sem qualquer sombra de dúvidas, o Ministério Público enquanto defensor da ordem jurídica nacional) o dever de intervir nas relações existentes entre consumidores e fomecedores, em contraponto às idéias neoliberais de livre comércio, que sempre foram arredias a qualquer forma de ingerência estatal, ou

${ }^{3}$ CFB/88 - Art. 5. ."Todos são iguais perante a lei, sem distinção de qualquer natureza, garantindo-se aos brasileiros e aos estrangeiros residentes no País a inviolabilidade do direito à vida, à liberdade, à iguaidade, à segurança e à propriedade, nos termos seguintes: (...) XXXII - o Estado promoverá, na forma da lei, a defesa do consumidor. ${ }^{\prime \prime \prime} O$ Congresso Nacional, dentro de cento e vinte dias da Promulgação da Constituição, elaborará o código de defesa do consumidor."

${ }^{4} \mathrm{ADCT}$ - Art. 48., da CF/88), o que fol feito, no entanto, somente em 11 de setembro de 1990 , com a Lei Federal $n^{\circ} 8.078$.

${ }^{5}$ Ver sobre o tema, a excelente obra de MORAES, Paulo Valério Dai Pai, O princípio da vulnerabilidade nos contratos e na publicidade e nas demais práticas comerciais. Editora Síntese, Porto Alegre, 1999. 
de atuação interventiva de qualquer organismo, principalmente a respeito deste tema.

A imposição constitucional de limites ${ }^{6}$ à livre iniciativa e a disposição da defesa dos consumidores entre os direitos e garantias fundamentais (espaço nobre que é da Constituição Federal Brasileira), dão conta, pois, da importância conferida pelo legislador constitucional ao tema consumerista. Sobre o assunto, JOSÉ AFONSO DA SILVA ${ }^{7}$ comenta que a inserção da defesa do consumidor entre as garantias fundamentais dá aos consumidores a "categoria de titulares de direitos constitucionais fundamentais". Lembra, ainda, que a elevação da defesa do consumidor à condição de princípio da ordem econômica tem "o relevante efeito de legitimar todas as medidas de intervenção estatal necessárias a assegurar a proteção prevista." ${ }^{\prime \prime}$

Com efeito, o descompasso entre a realidade da sociedade de consumo de massa dos dias atuais e a visão individualista da legislação até então vigente (antes de 1988) tornavam imprescindivel a edição de normas que viessem a tutelar os conflitos resultantes das relações de consumo. A respeito da predominância do individualismo nalegislação brasileira, lembra NELSON NERY JUNIOR ${ }^{9}$ que a mesma, com fundamento nos princípios individualistas do liberalismo econômico do século XIX (em especial no Códe Napoleon, de 1804, que influenciou tanto diplomas de direito material, quanto processual), foi idealizada "para a solução de lides eminentemente individuais".

${ }^{6}$ Sábias as palavras de COMPARATO, Fábio Konder. Novos ensaios e pareceres de Direito Empresarial, Rio de Janeiro, Forense, 1981, p. 297, apud CAMARGO, Ricardo Lucas. Breve introducão ao direito econômico. Porto Alegre: Sergio Antonio Fabris Editor, 1993, p. 50: "O critério da eficiência da organização de setor econômico, como razão fundante para a limitação da livre iniciativa, deve ser apreciado em termos jurídicos - mais exatamente constitucionais - e não puramente econômicos. Não se trata de entregar o julgamento do desempenho privado ao arbítrio incontrolável da tecnocracia, mas de dar aplicação em concreto aos valores expressos no art. 160 da lei maior.

7 SILVA, José Afonso da. Curso de Direito Constitucional Positivo. 21a ed. rev. atual, nos termos da Reforma Constitucional. São Paulo, Malheiros, 2002, pp. 237 e 238.

${ }^{8}$ SILVA, José Afonso da. Curso de Direito Constitucional Positivo, pp, 237 e 238. 9. Assim, JÚNIOR, Nelson Nery. Princípios gerais do código brasileiro de defesa do consumidor. Revista de Direito do Consumidor. São Paulo: Revista dos Tribunais, v. 3, setembro/dezembro 1992, p. 47 
Ante o panorama econômico-social e legislativo acima mencionado, fez-se forçosa a adequação da legislação pátria aos moldes das necessidades da sociedade atual, o que começou a ser feito pela Constituição Federal e, a seguir, pelo Código de Defesa do Consumidor. Havia-se tornado imprescindivel que os interesses da coletividade passassem a ser tutelados de uma forma mais adequada e eficaz, não mais sendo privilegiados, pois, interesses meramente patrimoniais de certos indivíduos. A própria Carta Magna indicou este norte ao estabelecer como objetivos fundamentais da República Federativa do Brasil o desenvolvimento nacional, a redução das desigualdades sociais, a construção de uma sociedade livre, justa e solidária e a promoção do bem de todos (art. $3^{\circ}, \mathrm{CF}$, e seus incisos).

Por outro lado, em que pese a referida evolução legislativa, resta ainda por ser efetivado o cumprimento aos princípios estabelecidos por nossa Constituição Federal, sendo que, neste caminho, o Órgão Ministerial possui a mais elevada responsabilidade, qual seja, o zelo à ordem jurídica nacional (art. 127, CF), e, com relação ao tema deste artigo, à promoção da defesas do consumidores, conforme estipulado no art. $5^{\circ}$, inciso XXXII, da CF.

Fato importante que realçamos desde logo, é que o art. $5^{\circ}$, inc. XXXII, constitui-se em cláusula pétrea da Lei Fundamental Brasileira, ou seja, é dispositivo constitucional imutável (art. $60, \S 4^{\circ}$, CF/88), não podendo ser alterado nem mesmo por via de Emenda à Constituição. O objetivo do legislador, neste caso, foi o de impedir inovações temerárias em assunto crucial para a cidadania e para o próprio Estado brasileiro.

3. Fundamentos da atuação do Ministério Público na defesa dos Consumidores

Conforme estipula a Constituição brasileira de 1988, em seu art. 127, o Ministério Público é "instituição permanente, essencial 
à função jurisdicional do Estado, incumbindo-Ihe a defesa da ordem jurídica, do regime democrático ${ }^{10}$ e dos interesses sociais e individuais indisponíveis". Não é outra senão a previsão legal constante da Lei Federal ${ }^{\circ}$ 8.625, de 12 de fevereiro de 1993 - Lei Orgânica do Ministério Público Nacional - LONMP -, que repete o disposto na Constituição brasileira.

Sobre as atribuições do Ministério Público, KASUO WATANABE ${ }^{11}$ escreve que compete ao Órgão Ministerial, além da promoção dos interesses e direitos difusos e coletivos prevista no art. 127 da Constituição Federal, a defesa dos interesses ou direitos dos consumidores quando se tratar de interesses individuais, "desde que homogêneos e tratados coletivamente". Segue o citado autor a referir que, não fosse assim, tornar-se-ia o Ministério Público um "defensor de interesses individuais disponiveis, quando a sua atribuição é mais relevante".

Com efeito, não podemos olvidar, trata-se de verdadeiro dogma da Instituição, a preocupação com a proteção de direitos e interesses da coletividade (difusos, coletivos e individuais homogêneos). Entretanto, cumpre destacarmos, em contraposição ao acima afirmado pelo citado autor, que também podem e devem ser alvo de proteção por parte do Ministério Público os interesses e direitos individuais disponíveis, desde que presentes dois requisitos, o interesse públicoe a relevância social na questão posta à análise do Parquet.

${ }^{10}$ Conforme leciona MAZZILLI, Hugo Nigro, em sua obra intitulada Regime Jurídico do Ministério Público, 33 edição, rev, atual., 1996, p. 1 e 2, "à exceção da referência à defesa do regime democrático contribuição da Carta de Curitiba, que por sua vez se inspirou na Constituição Portuguesa de 1976 -, os demais elementos da definição constitucional provieram da Lei Complementar n. 40, de 14 de dezembro de 1981 - a primeira Lei Orgânica Nacional do Ministério Público, hoje sucedida pela Lei $8.625 / 93 . "$.

11 WATANABE, Código Brasileiro de Defesa do Consumido - comentado pelos autores do anteprojeto, 4. ed. Forense Universitária, 1999, p. 734-736. 
Sobre o tema, PAULO VALÉRIO DAL PAI MORAES ${ }^{12}$ e HUGO NIGRO MAZZILI ${ }^{13}$, no que concordamos, discorrem que, para que haja obrigatoriedade de atuação do Parquet, em qualquer tipo de ação judicial, basta sejam identificados o interesse público e a relevância social da matéria, evidenciados pela "dimensão ou característica do dano" ou pela "relevância do bem jurídico a ser protegido"14.

Sobre o assunto; merece destaque a lição de ADA PELLEGRINI GRINOVER ${ }^{15}$, que vem ao encontro de nossa tese. Discorre a ilustre autora que:

\section{O MINISTÉRIO PÚBLICO COMO AUTOR - Não bastasse a} legitimação a toda e qualquer ação coletiva, conferida ao Ministério Público pelo art. 82, ao qual o art. 91 faz remissão, o próprio art. 92 reforça a idéia da titularidade do Parquet para o processo tratado no Capitulo ora em exame. Apesar disso, tem havido alguns pronunciamentos judiciais contrários ao reconhecimento da legitimação do Ministério Público às ações coletivas em defesa de interesses individuais homogêneos, por considerarem inconstitucional a extensão da legitimação operada pela lei ordinána. Argumenta-se em prol dessa orientação como art. 129, lil, CF, que só se refere à legitimação ao MP para a defesa de interesses difusos e coletivos. Nem tem bastado para essa tendência o argumento da extensão das funções do MP a outras que the sejam atribuídas por lei, desde que compatíveis com sua finalidade (inc. IX do art. $129, C F$ ), porquanto se afirma que o MP, nos termos do art. 127, CF, é preordenado à defesa

12 MORAES, Paulo Valério DaI Pai. O Ministério Público e a legitimidade para a defesa dos interesses coletivos decorrentes de questões tributárias de massa. In, Revista do Ministério Público, n 43, pp. 51 -104, p. 52.

${ }_{13}$ MAZZILLI, Hugo Nigro. O Ministério Público na Constituicão de 1988. Ed. Saraiva, São Paulo, 1989,p.48.

14 Vide, $\S 1^{\circ}$ do art. 82 do Código de Defesa do Consumidor (que nos informa o elenco de legitimados para a propositura de ações na defesa dos consumidores). 15 GRINOVER, Ada Pellegrini. Código Brasileiro de Defesa do Consumido comentado pelos autores do anteproieto, 4, ed. Forense Universitária, 1999, p. 545-6: 
de 'interesses sociais e individuais indisponiveis', e osinteresses individuais homogêneos seriam disponiveis. E, na mesma linha, aduzse também a circunstância de que, a admitir-se a legitimação do MP para casos tais, estaria se retirando do cidadão a liberdade de escolha, não se podendo obrigar ninguém a ter um direito reconhecido contra a sua vontade. Ora, em primeiro lugar cumpre notar que a Constituição de 1988, anterior ao $C D C$, evidentemente não podena aludir, no art. 129,111, à categoria dos interesses individuais homogêneos, que só viria a sercriada pelo Código. Mas na dicção constitucional, a ser tomada em sentido amplo, segundo as regras da interpretação extensiva (quando o legislador diz menos de quanto quis), enquadra-se comodamente a categoria dos interesses individuais, quando coletivamente tratados. Em segundo lugar, a doutrina internacional e nacional, já deixou claro que a tutela de direitos transindividuais não significa propriamente defesa de interesse público, nem de interesses privados, pois os interesses privados são vistos etratados em sua dimensão social e coletiva, sendo de grande importância política a solução jurisdicional de conflitos de massa. Assim, foi exatamente arelevância social da tutela coletiva dos interesses ou direitos individuais homoQêneos que levou o leqislador ordinário a conferir ao MPe a outros entes públicos a leqitimação para aQir nessa modalidade de demanda, mesmo em se tratando de interesses ou direitos disponíveís. Em conformidade, aliás, coma própria Constituição, que permite a atribuição de outras funcões ao $M P$, desde que compativeis com sua finalidade (art. 129, IX);e a dimensão comunitária das demandas coletivas, qualquer que seia seu obieto, insere-se sem dúvida na tutela dos interesses sociais referídos no art. 127 da Constituição. Quando muito poder-se-ia exigir, caso a caso, que se aferisse a relevância social do objeto da demanda coletiva em defesa em defesa de interesses individuais homogêneos, para o reconhecimento da legitimação do MP. E isso poderia ser feito na esteira do disposto no art. 82 , par. $1^{\circ}$, $C D C$, para a dispensa do requisito da pré-constituição para as associações. Mas não tem sentido a afirmação da inconstitucionalidade dessas açôes. Nem se pode argumentar como 
fato de a titular idade à ação coletiva em defesa de interesses individuais homogêneos impor aos beneficiários da sentença condenatónia um direito, que talvez não queiram exercer. A sentença condenatóna, na técnica brasileira, apenas reconhece a existência do dão genérico e o dever de indenizar. Caberá à iniciativa de cada beneficiário habilitar-se à liquidação da sentença incumbindo--the provar ainda a existência do dano pessoal, se u nexo etiológico como dano geral reconhecido pela sentença e quantificar o montante da indenização. Respeita-se, assim, a autonomia da vontade de cada indivíduo que, se não quiser fruir do direito que the foi reconhecido, simplesmente não o exercerá. Apesar de alguma divergência, a linha predominante é no sentido do reconhecimento da legitimação, havendo casos em que esta é negada não em face de sua eventual inconstitucionalidade, mas porque se trata, na espécie, de pequeno número de interessados, estritamente definido. Nessa última linha, a legitimação é negada em face da caracterização mais estreita dos interesses individuais homogêneos, que não ocorreriam na espécie.

Desta forma, como se pode observar, o Ministério Público possui mais do que legitimidade para atuar na defesa dos consumidores, (e não simplesmente daqueles considerados sctricto sensu, mas também dos equiparados, seja por força do artigo 17 ou do artigo 29 do CDC, uma vez que o Código de Defesa do Consumidor serve para proteger todos aqueles que às situações legais do referido Código se enquadrem. Tal conclusão decorre, fundamentalmente, do fato de que a própria Constituição brasileira impõe: l) a defesa do consumidor (art. $5^{\circ}$, inciso XXXII); II) limites à livre iniciativa (art. 170, inciso V); e, III) ao Ministério Público, a defesa da ordem jurídica nacional e a proteção dos interesses sociais e individuais indisponiveis (art. 127).

Ultrapassada, portanto, a questão relativa ao dever de atuação do Ministério Público na defesa e proteção de direitos individuais homogêneos ou coletivos disponíveis. Assim, em matéria consumerista, deve o Ministério Público atuar mesmo quando demandado por apenas um consumidor vulnerável (stricto sensu-art. $2^{\circ}, \mathrm{CDC}$ - ou equiparado - arts. 17 e 29, CDC), mas desde que presentes a relevância sociale o 
interesse público da proteção não daquele único consumidor, mas de uma gama de consumidores que estejam sendo lesados ou na iminência de o serem. A atuação do Parquet, nestes casos, trará, sim, reflexos positivos para a "limpeza" do mercado de consumo brasileiro.

Para aqueles que mesmo assim não se tenham por convencidos da tese aqui exposta, convém destacarmos que 0 art. $1^{\circ}$ do Código de Defesa do Consumidor prevê que as normas contidas no referido diploma legal são de ordem pública e de interesse social, nos termos dos arts. $5^{\circ}$, inciso XXXII, 170 , inc. V, da Constituição Federal e art. 48 de seus ADCT, o que, por si só, já demandaria a atuação do Órgão Ministerial.

Sobre a natureza das normas de ordem pública, trazemos à baila o ensinamento de JOSÉ GERALDO BRITO FILOMENO ${ }^{16}$, que leciona que as mesmas são inderrogáveis por vontade das partes, ou seja, não passíveis de disposição. Também sobre o assunto, cabe lembrarmos o ensinamento de NELSON NERY JUNIOR ${ }^{17}$, que afirma que qualquer conflito resultante de temas como este, cujas normas são de ordem pública, deve ser, obrigatoriamente ${ }^{18}$, examinado ex officio pelo julgador, não havendo, desta forma, necessidade de sua provocação por nenhuma parte interessada, uma vez que o princípio do dispositivo não tem incidência em questões desta natureza. Outro

${ }^{16}$ Veja, FILOMENO, Código brasileiro de defesa do consumidor comentado pelos autores do anteproieto, p. 24. O autor excetua a regra de indisponibilidade dos referidos direitos, aos casos em que os interesses envolvidos sejam de caráter patrimonial. Cita como exemplo a "Convenção Coletiva de Consumo". Ainda a respeito da natureza das normas de proteção do consumidor, ver: MORAES, Paulo Valério DaI Pai, Código de Defesa do Consumidor: o princípio da vulnerabilidade no contrato. na publicidade e nas demais práticas comerciais. Porto Alegre: Síntese. 1999, p. 115, onde conceitua o que sejam normas de ordem pública.

17 JUNIOR, Nelson Nery. Recursos no Processo Civil: Princípios Fundamentais e Teoria Geral dos Recursos. São Paulo: Revista dos Tribunais, 1990, n. 3. p. 51. 18 Referimo-nos ao poder-dever a que estão ungidos os julgadores. Quanto ao tema, indicamos a obra do professor JÚNIOR, José Cretella. Curso de direito administrativo. 133 ed. Rio de Janeiro, Brasil: Forense, 1995, que afirma ser 0 "poder-dever", "a faculdade discricionária da Administração de limitar, dentro da lei, as liberdades individuais em prol do interesse coletivo". 
destaque importante referido por este autor, diz respeito ao fato de que neste tipo de matéria não ocorre a preclusão, podendo ${ }^{19}$, assim, as questões de direito do consumidor serem decididas a qualquer tempo e em qualquer grau de jurisdição, além da possibilidade de haver em julgamentos em grau de recurso, a chamada reformatio in pejus permitida ${ }^{20}$.

Assim, todo e qualquer delito ou prática infrativa realizados no mercado de consumo deve ter por parte do Estado brasileiro ação ou reação, capaz de prevenir possíveis lesões aos direitos dos consumidores ou repreender os fornecedores pela prática de atos danosos $^{21}$. E aqui se insere o Ministério Público enquanto defensor da ordem jurídica nacional e de interesses sociais e individuais disponiveis (desde que presentes os requisitos da relevância social e do interesse social) ou indisponíveis (como é o caso das normas contidas no Código de Defesa do Consumidor).

Com efeito, é o que se pretende com o Código Brasileiro de Defesa do Consumidor, pois dentre os princípios fundamentais da Política Nacional de Relações de Consumo para a proteção efetiva dos consumidores está o da "a coibição e repressão eficientes de todos os abusos praticados ${ }^{22}$, pela "presença do Estado no mercado de consumo"23.

O art. $4^{\circ}$ do CDC, dá o norte ao Ministério Público, assim como a todos os órgãos integrantes do Sistema Nacional de Defesa do Consumidor, para a atuação na fiscalização das relações de consumo e para a instauração de expedientes administrativos ( v.g., peças

19 Podendo" no sentido de haver opção ao julgador, quanto ao tempo para o julgamento de conflitos que contenham normas desta natureza. A obrigatoriedade do seu exame faz-se necessária, como afirma o próprio JÚNIOR, Nelson Nery. Princípios gerais do código brasileiro de defesa do consumidor. p. 51 .

20 JUNIOR, Nelson Nery. op. cit., p. 52.

${ }^{21}$ Assim, BITT AR, Carlos Alberto. Direitos do consumidor: código de defesa do consumidor, 53 ed. Rio de Janeiro: Forense Universitária, 2002, pp. 74-76.

22 Vide art. $4^{\circ}$, inc. VI do CDC.

23 vide. art. $4^{\circ}, 11$, " $\mathrm{C}^{\prime \prime}, \mathrm{CDC}$. 
informativas e inquéritos civis no âmbito do MP) com vistas à investigação e preparação de ações que objetivem a punição das práticas infrativas realizadas no mercado. O objetivo primordial é garantir a defesa não simplesmente daquele consumidor prejudicado (considerado individualmente) - objetivo secundário-, mas a defesa de uma coletividade de consumidores - objetivo primário. Tudo isto, sempre se tendo em vista o princípio esculpido no CDC, do "reconhecimento da vulnerabilidade do consumidor no mercado de consumo ${ }^{24}$.

O direito a ser protegido pelo Parquet deve, portanto, possuir como características principais, e preliminares, a relevância e o interesse social, o que, realmente se vê nos direitos dos consumidores, que basta lembrar a preocupação mundial com relação ao tema. Neste sentido, salientamos, aqui, apenas como representativo da relevância supranacional da defesa dos consumidores, a Resolução 39/248, de 16 de abril de $1985^{25}$, adotada pela ONU em sua $39^{\mathrm{a}}$ sessão ${ }^{26}$.

Com relação às funções institucionais do Ministério Público, frisamos, por fim, dentre aquelas que têm pertinência ao tema do presente artigo, que a Constituição da República, explicita que compete ao Parquef ${ }^{27}$

${ }^{24}$ Vide art. $4^{\circ}$, inc. I, do CDC.

${ }^{25}$ Veja publicação na íntegra em FILOMENO, Manual de direitos do consumidor. São Paulo: Atlas, 2001, pp. 506-511.

${ }^{26}$ Ver mais sobre o tema em nosso, Tutela Administrativa dos Consumidores no Brasil como Paradigma aos Países do Mercosul, Curitiba : Ed. Juruá, 2003, pp. 21 a 25, ou em nosso artigo A intervencão estatal brasileira nas relacões de consumo: Estrutura legislativa e fundamentos, Revista de Direito do Consumidor, $n^{\circ} 50$, Ed. RT, 2004, pp. 58 a 70 . rei (daí lês gens du roi), antes de adquirirem a condição de magistrados e de terem assento ao lado dos juízes, tiveram inicialmente assento sobre o assoalho (parquet) da sala de audiências, em vez de terem assento sobre o estrado, lado a lado à magistrature assise (magistratura sentada)...

${ }^{27}$ A expressão Parquet é, segundo MAZZILLI, Rugo Nigro. Regime Jurídico do Ministério Público. São Paulo: Saraiva, 1996, p. 5, influência da doutrina francesa. 
Tal expressão provém da tradição francesa de mencionar o Ministério Público como Parquet (assoalho). Segundo o referido autor, "os procuradores do:

a) o zelo pelo efetivo respeito dos poderes públicos e dos serviços de relevância pública aos direitos assegurados na Constituição Federal, devendo, para tanto, promover as medidas necessárias à sua garantia;

b) a promoção do inquérito civil e da ação civil pública, para a proteção do patrimônio social, do meio ambiente e de outros interesses difusos e coletivos - compreendido, neste item, a defesa dos consumidores;

c) a expedição de notificações, através dos quais requisitará informações e documentos a fim de instruir procedimentos administrativos de sua competência (inquéritos civis, v.g.); e,

d) a requisição de diligências investigatórias bem como a instauração de inquérito policial, sem prescindir de fundamentação jurídica em suas manifestações processuais.

\section{O Consumidor para o Código de Relações de Consumo}

Encontram-se na legislação brasileira, e especificamente no Código de Relações de Consumo, três ${ }^{28}$ conceitos de consumidor. Estão eles previstos no caput do art. $2^{\circ}$, e nos arts. 17 e 29 do CDC e definem, respectivamente:

I)consumidor final (stricto sensu);

${ }^{28}$ Concordamos com SILVIO LUIS FERREIRA DA ROCHA, Responsabilidade civil do fornecedor pelo fato do produto no direito brasileiro. São Paulo: RT, 1992,p. 66, que entende que o Código de Defesa do Consumidor apresenta três conceitos de consumidor, desconsiderando o previsto no parágrafo único do art. $2^{\circ}$, com relação aos consumidores considerados coletivamente. 
11) consumidores equiparados pelo fato do produto ou do serviço (acidentes de consumo).

O conceito de consumidor final em nossa legislação pátria é encontrado no art. $2^{\circ}$ do CBDC. Dispõe expressamente o mencionado artigo que: "Art. $2^{\circ}$. Consumidor é toda pessoa física ou jurídica que adquire ou utiliza produto ou serviço como destinatário final.

Necessário discorrermos sobre a existência de duas correntes de pensamento a respeito do art. $2^{\circ}$, caput, do Código de Defesa do Consumidor, conforme muito bem identificadas pela ilustre Profa. Dra. Cláudia Lima Marques em sua obra Contratos no Código de Defesa do Consumidor: o novo regime das relações contratuais. p. 252 e ss. São elas as correntes finalista e a maximalista. Para a corrente finalista, a base da proteção consumerista é a conceituação de consumidor, ou seja, os finalistas querem restringir quem seja a figura do destinatário final, para se saber quem está e quem não está sob a égide do Código Protetivo. A questão fundamental para esta corrente é a vulnerabilidade do consumidor. Propõem os pensadores que a esta corrente se filiam, dentre eles Cláudio Bonatto, que o art. $2^{\circ}$, caput, deve ser interpretado da forma mais restritiva possivel a fim de que se encontre o verdadeiro alvo das normas consumeristas. Pois bem, como distintamente leciona Cláudia Lima Marques, para os finalistas "destinatário final é aquele destinatário fático e econômico do bem ou serviço, seja ele pessoa jurídica ou física." Assim, não basta a retirada do produto ou do serviço como destinatário final fático do bem ou do serviço, mas faz-se necessário que o adquirente ou contratante, ou aquele que venha a utilizar o produto ou serviço, o retire do mercado sem qualquer ato ou intenção de desenvolver atividades de produção, montagem, criação, construção, transformação, importação, exportação, distribuição ou comercialização dos produtos ou prestação dos serviços. No entanto, convém lembrarmos que apesar de restritiva e teleológica a interpretação da norma por esta corrente, a justiça vem entendendo a existência de vulnerabilidade de pequenas empresas, o que tem amenizado a posição inicial dos pensadores finalistas. Por outro lado, para a corrente maximalista, o Código de Defesa do Consumidor é norma geral 
orientadora do mercado de consumo. Nas irretocáveis palavras da professora Cláudia Lima Marques, "o CDC seria um Código geral sobre o consumo, um Código para a sociedade de consumo, o qual institui normas para todos os agentes do mercado, os quais podem assumir os papéis ora de fornecedores, ora de consumidores." Ainda segundo a renomada autora, o caput do art. $2^{\circ}$ do CDC deve ser interpretado "o mais extensamente possivel (...) para que as normas do CDC possam ser aplicadas a um número cada vez maior de relações no mercado".

A corrente maximalista, ao contrário da finalista, entende que a interpretação que deve ser feita do artigo aqui examinado deve ser puramente objetiva, bastando para ser considerado destinatário final do produto aquele que simplesmente o retira do mercado de consumo, o consome, independentemente do seu destino econômico. Exemplo disto podemos citar a compra de um computador para um escritório.

Apesar de entendermos que se trata o Código de Defesa do Consumidor de um conjunto de normas a regular, por regras próprias, 0 mercado de consumo brasileiro (a aparentar que nos filiamos à corrente maximalista), não podemos concordar com a extensão indiscriminada do conceito de consumidor final para os chamados profissionais, ou seja, não aceitamos que aqueles que retiram o produto do mercado de consumo para utilizá-lo com um fim profissional, na sua área de atuação comercial, se aproveitem das normas consumeristas para a obtenção de vantagens escusas. Devemos ter sempre presente a idéia de que o CDC tem o fito de harmonizar as relações de consumo, que são, por sua própria natureza, desiguais. Só teremos relação de consumo, nestes casos, quando se verifique, de fato, na relação originariamente mercadológica, uma vulnerabilidade evidente do adquirente profissional do produto ou do serviço ou uma prática infrativa que se evidencie no mercado de consumo, com o que a proteção daquela relação jurídica traria benefícios e reflexos positivos para as demais relações jurídicas existentes com aquele fornecedor.

De outra banda, nos parece também evidente o objetivo do legislador em proteger o mercado de consumo brasileiro, pois equipara 
a consumidor o terceiro interveniente de uma relação contratual de consumo que tenha sido vítima de um evento danoso ocasionado por um produto e/ou serviço defeituosos (o bystander, na terminologia da common law).

Neste mesmo sentido, é que equiparam-se a consumidores aqueles que sejam expostos às práticas comerciais previstas nos arts. 30 a 44 do CDC. A existência de conceitos extensivos de consumidor, autoriza, portanto, a aplicação das regras do Código Consumerista até mesmo àqueles que sequer tenham adquirido ou venham, por exemplo, adquirir um produto ou contratar um serviço, ou, simplesmente, que não sejam considerados consumidores em sentido estrito. Podemos, aqui, citar dois exemplos disto:

"A" solicita, aleatoriamente, uma carona em uma determinada estrada. Ao pegar a carona, logo a seguir, o veículo em que ele se encontra apresenta falha no sistema de freios e choca-se contra a traseira de um caminhão, vindo " $A$ " a sofrer lesões em virtude disto. Neste caso, temos o chamado "acidente de consumo". Há uma pessoa, (caroneiro) " $A$ ", que não adquiriu o veículo, mas que em virtude do acidente ter ocorrido em razão de falha no produto (falha no sistema de freios) tomouse vítima de evento danoso. Poderá "A" pleitear, destarte, indenização com base no próprio Código, aproveitando-se, da regra extensiva do conceito de consumidor prevista no art. 17 do Código de Defesa do Consumidor.

"A", pessoa jurídica de direito público está sendo alvo de cobrança de tributos indevidos em sua conta de telefone, o que é considerado pelo art. 39 , inciso $V$ do $C D C$, obtenção de vantagem ilícita por parte da Concessionária de telefonia. "A" poderá ser considerada consumidora equiparada por força do art. 29 do Código de Defesa do Consumidor, pois está exposta à uma das práticas comerciais abusivas prevista no Capítulo V do CDC. 


\section{BIBLIOGRAFIA}

BENJAMIN, Antônio Herman Vasconcellos e. O transporte aéreo e o Códiqo de Defesa do Consumidor. AJURIS, Porto Alegre, mar. 1998, número especial.

BITTAR, Carlos Alberto. Direitos do consumidor: códiqo de defesa do consumidor, 5a ed. Rio de Janeiro: Forense Universitária, 2002.

BONATTO, Cláudio. Códiqo de defesa do consumidor: cláusulas abusivas nas relações contratuais de consumo. Porto Alegre. Livraria do Advogado, 2001.

DORNELES, Renato Moreira. Tutela Administrativa dos Consumidores no Brasil como Paradiqma aos Países do Mercosul. Curitiba: Ed. Juruá, 2003.

A intervenção estatal brasileira nas relações de consumo: Estrutura leqislativa e fundamentos, Revista de Direito do Consumidor, $n^{\circ} 50$, Ed. RT, 2004, pp. 58 a 70.

FILOMENO, José Geraldo Brito. Manual de direitos do consumidor.São Paulo:Atlas, 2001.

JÚNIOR, José Cretella. Curso de direito administrativo. 13a ed. Rio de Janeiro, Brasil: Forense, 1995.

JUNIOR, Nelson Nery. Recursos no Processo Civil: Princípios Fundamentais e Teoria Geral dos Recursos. São Paulo: Revista dos Tribunais. 1990, n. 3. p. 51.

Nelson Nery. Princípios qerais do códiqo brasileiro de defesa do consumidor.p. 51. 
MAZZILLI, Hugo Nigro. Reqime Jurídico do Ministério Público. São Paulo: Saraiva, 1996.

Saraiva, São Paulo, 1989.

, OMinistério Público na Constituição de 1988. Ed.

MARINS, James. Responsabilidade da empresa pelo fato do protudo: os acidentes de consumo no Códiao de Proteção e Defesa do Consumidor. São Paulo: RT, 1993.

," Proteção contratual do CDC a contratos interempresariais. inclusive bancários. In Revista de Direito do Consumidor, $n^{\circ}$ 18, abr/jun 1996.

MARQUES, Cláudia Lima. Contratos no Códiao de Defesa do Consumidor: o novo regime das relações contratuais, 4a ed. São Paulo: RT, 2002.

MORAES, Paulo Valério Dai Pai. O compromisso de aiustamento. In: Revista do Ministério Público, $n^{\circ}$ 42, pp. 43-81.

„O princípio da vulnerabilidade nos contratos e na publicidade e nas demais práticas comerciais. Editora Síntese, Porto Alegre, 1999.

"O Ministério Público e a leaitimidade para a defesa dos interesses coletivos decorrentes de Questões tributárias de massa. In, Revista do Ministério Público, $\mathrm{n}^{\circ}$ 43, pp. 51-104, p. 52.

ROCHA, Silvio Luis Ferreira da. Responsabilidade civil do fornecedor pelo fato do produto no direito brasileiro. São Paulo: RT, 1992.

SANSEVERINO, Paulo de Tarso. Responsabilidade civil no códiao do consumidor e a defesa do fornecedor. São Paulo: Saraiva, 2002. 